\title{
Notas para una filosofía de la educación intercultural abiayalense
}

\author{
Notes for a philosophy of abiayalense intercultural \\ education \\ Recepción: Diciembre - 2008 \\ Aprobación: Abril - 2009 \\ Carlos María Pagano Fernández* \\ “Los blancos, cuando hablan, hacen una ponencia; nosotros damos un testimonio" (Jorge Terena) \\ ¿Cómo han de salir de las universidades los gobernantes, si no hay universidad en América donde se enseñe lo \\ rudimentario del arte del gobierno, que es el análisis de los elementos peculiares de los pueblos de América? A adivinar \\ salen los jóvenes al mundo, con antiparras yanquis o francesas, y aspiran a dirigir un pueblo que no conocen (José Martí, \\ Nuestra América).
}

\section{RESUMEN}

La educación intercultural se convierte en un imperativo global. Hasta las empresas multinacionales hablan de la necesidad de contar con personal capacitado interculturalmente. El continente Abia Yala no está ajeno a esta atmósfera. Por su parte, la filosofía, como cuestionadora permanente de todo statu quo en aras a crear las condiciones para hacer realidad una humanización solidaria más plena, debe hacerse cargo de esa función crítica, no siempre cómoda, con el fin de que lo reconocido como necesario y que va configurando una atmósfera mundial en las propuestas educativas, mantenga su creativa vigilia frente a las instrumentaciones que pueden desvirtuar el propósito educativo intercultural. La filosofía debe realizar el primer cuestionamiento frente a sí misma y sus modos de educar filosóficamente, puesto que el eurocentrismo interiorizado de la educación filosófica académica asegura la hegemonía cultural gnoseológica en la que hace pie el monótono ritmo del tiempo y del espacio sancionado por el mercado como única posibilidad cultural pedagógica y civilizatoria mundial. La filosofía intercultural no se queda en sí misma, cómplice del proyecto mercantil neoliberal; debe formular sus propuestas para mantener la guardia a fin de que la educación intercultural no se convierta en fachada que esconde su asimilación sistémica deshumanizante y depredadora de culturas, del mismo modo que el mercado procede con el medio ambiente, pues con ello no pasaría de una nueva herramienta neocolonial depredadora de la vida natural y humana.

PALABRAS CLAVE: Interculturalidad, Educación, Filosofía, Antropología neoliberal

\section{ABSTRACT}

Intercultural education becomes a global imperative. Even multinational enterprises talk about the need of counting with interculturally trained personnel. The Abia Yala continent is not strange to this atmosphere. On its part, philosophy, as a permanent inquiry of its status quo aiming to create the conditions to make real a more complete human solidarity, should be in charge of this critic function, not always comfortable, with the objective to make what was acknowledged as necessary and which configures a worldwide atmosphere on educational proposals, keep its creative sight when facing instrumentations that can fake the educational intercultural purpose. Philosophy should do the first inquiry against itself and its way to educate philosophically, since the eurocentrism interiorized of academic philosophical education ensures gnoselogic cultural hegemony, in which falls the monotonous rhythm of time and space, punished by the market as a unique cultural and worldwide civilizing pedagogical possibility. Intercultural philosophy does not stay on itself, being a collaborator of the mercantile neoliberal project; it must formulate proposals to keep attentiveness with the purpose of not turning intercultural education into a frontispiece that hides its systematic alienating and predating assimilation of cultures, in the same way that the market proceeds with environment, since with this it would not evolve from a neocolonial tool predator of natural and human life.

KEY WORDS: Interculturality, education, philosophy, neoliberal anthropology

\footnotetext{
* Pertenece al Claustro de graduados de la UNSa, es Profesor y Licenciado en Filosofía por esa casa (1978 y 1982 respectivamente) y Doctor en Filosofía por la Rheinsch-Westfälische Technische Hochschule Aachen (Aquisgrán), Alemania (1999).Correo: carmapagano@yahoo. com.ar
} 


\section{Aclaración introductoria previa}

Relacionar la EIB con la renovación de las políticas educativas, como reza el lema de este congreso, invita al que ensaya el oficio filosófico de "ser testigo incómodo" del tiempo y de meterse "en cosas que (aparentemente) no le importan"1, a plantearse si tiene algo que decir sobre el lema convocante. Pues cuando se trata de renovar la educación, se está tocando fondo, por decir así, en el propósito del educar. Asumiendo el amplio desarrollo de las ciencias de la educación y su fundamental rol en esa tarea, lo decisivo a la hora de las renovaciones educativas radica en la imagen del hombre y del mundo que determinará el rumbo a seguir que se dice nuevo. $Y$ en la medida en que esos rumbos pretendan ser orientados por el espíritu de una época signada por la homogeneización mundial de la barbarie capitalista que esparce el fantasma de la exclusión de más de 2.000 millones de seres humanos y de una crisis ambiental límite, también aparece ese "testigo incómodo", no tanto a especular sistemas para una filosofía de la El sino, a modo de estocadas contextuales, como pretendo acá, proponer solo unas notas de advertencia para no caer en la trampa de la época con su costumbre de instrumentar la educación "al compás del dinero" ${ }^{2}$ y sus mandatos y condicionamientos en la política educacional.

Hablar de interculturalidad haciéndola: ¿por qué abiayalense?

Con la primera estocada, quisiera explicar la última parte del título de mi aporte: el término abiayalense. Pues lo primero que debe hacer una conciencia que cala en el Ukhu Pacha o Minche Mapu de lo intercultural, más allá de modas y clichés en uso para hacernos creer que lo somos, es situarse en contexto y actitud de aprendizaje, ya que hablamos de educación, de aquello que los diversos nos traen como su riqueza y que puede abrir los propios panoramas de sentido. Digo esto con intención precisa de asumir algo que, al tratar la El, se suele ocultar como inexistente y, sin embargo, está a flor de piel, a saber: en este foro, llamado aún "latinoamericano", nos encontramos personas y grupos procedentes, al menos, por una parte, de pueblos indígenas, originarios, aborígenes $\mathrm{y}$, por otra, aquellos que procedemos de la cultura hegemónica, dominante, que organiza estos congresos, que los estructura a su manera, que establece las pautas de participación y de desarrollo por la simple realidad de que tiene el poder político y económico para hacerlo. Aclaro que yo, como descendiente de aborígenes españoles en un $50 \%$ y de aborígenes italianos en el otro $50 \%$, escolarizado en un instituto también llamado de "humanidades" clásicas y egresado de áreas humanísticas universitarias de fuerte cuño eurocéntrico -, lo cual es contradictorio, pues no puede ser humanista un espíritu excluyente, como el eurocéntrico - me incluyo en este segundo grupo, es decir, en el de los que provenimos de la cultura dominante eurocéntrica. Los estados nacionales de Abia Yala han sido conformados desde esta cultura dominante y de dominio, sin la menor impronta intercultural, como lo advierte ya José Martí en $1891^{3}$, y que en espíritu intercultural debe ser sometida a una "crítica de la razón india"4. Se debe decir que hablar de cultura dominante es hablar de poder, opresión, violencia e injusticia $^{5}$, aunque esto sea delicado y sistemáticamente solapado bajo diversos eufemismos. Ahora bien, uno de los actos de dominación que pertenecen ab-origine al coloniaje hegemónico y dominante de Abia Yala, es bautizarla como América, demarcar sus partes como latinas y no latinas, Latinoamérica, que da el adjetivo gentilicio de este VIII Congreso. En efecto, tanto nombrar el continente América como uno de sus grandes sectores Latinoamérica, de donde proviene latinoamericano, no es sino uno y el mismo acto continuo de indiscutible ejercicio-de-poder-sobre aquello que subyace como substrato histórico al proceso

1 Fornet-Betancourt, R., 2006, 12.

2 Bockelmann, Eske, Im Takt des Geldes. Zur Genese modernen Denkens, Springe, 2004.

3 Roig, A., Necesidad de una segunda independencia, 2007, pp. 30ss.; "La colonia continuó viviendo en la república...”, Martí, José, Nuestra América, en www.josemarti.org/jose_marti/obras/articulos/nuestramerica/01nuestramerica.htm

4 Bonfil B. G., 1995, 10.

Fornet-B., 2006a, p. 35 
de vasallaje iniciado hace 516 años frente a los pueblos aborígenes y sus culturas. Como lo he destacado en otra parte, cabe asumir el "nombre propio" con el que fue nombrado el continente desde la memoria varias veces milenaria en el Consejo Mundial de Pueblos Indios en Port Alberni, Vancouver, Canadá, en septiembre de 1975, con el nombre kuna Abia Yala, que, entre otros, alude al significado de "tierra en plena madurez" o "tierra de los grandes ríos, tierra de los hombres". Pese a mi origen cultural latinoamericano, solo uso Abia Yala porque hemos de intentar el ejercicio de modos concretos interculturales, es decir, hemos de educarnos nosotros mismos en lo intercultural, lo cual incluye poner en tela de juicio el horizonte y la matriz de la propia procedencia cultural, más cuando ésta pretende su universalización hegemónica, para abrirnos dialogalmente a la justicia paritaria que presupone esa El, frente a los "señores naturales"6 que hicieron vivible desde decenas de milenios Nuestra Abia Yala. Su adjetivo derivado es abiayalense ${ }^{7}$, y permítaseme finalizar este comienzo, por así decir, con la propuesta de que acá se determine que a partir del IX Congreso de EIB sea erradicado definitivamente el calificativo latinoamericano e, insisto, en praxis efectiva de interculturalidad, sea sustituido por IX, X, etc., Congreso Abiayalense de EIB.

\section{Filosofía intercultural para una filosofía de la educación intercultural}

Para continuar aclarando algo nuestro título, quisiera poner como segunda estocada una tesis, que bien se puede entrever en el de este punto: solo desde la filosofía inter- cultural es posible encarar una filosofía de la educación intercultural. Esta afirmación no procede de una sofisticada especialidad de la filosofía enclaustrada en claustros académicos. Nuestro propósito es diferente pues, como no podría ser de otro modo, tiene su raíz en la interpretación de la "actividad" filosófica como un complicarse en el servicio público del pensar que asume en forma dialogal lo que aquellas y aquellos con quienes se convive en la plural sociedad de diversas culturas, necesitan sea puesto sobre el tapete, para que esa misma sociedad plural se reconozca en sus direcciones existenciales de ir construyendo comunitariamente la plenitud humana - educándose y educando- mediante la liberación de lo que oprime, la rebeldía frente a lo que la niega y la clarificación de los sentidos de su intención directriz histórica, su "existencia misma"8, y que podemos traducir como los sueños o utopías que animan y hacen viviente esa plural comunidad en medio de los problemas que se le plantean.

No puedo extenderme en referir los ya amplios caminos recorridos por la filosofía intercultural para caracterizar este género distinto del filosofar ${ }^{9}$. Es cometido de la FI deslegitimizar la hegemonía grecorromana y euro-occidental, poniendo en crisis su pretendida universalidad y normatividad para la filosofía, al afirmar que tiene un origen "plurilocal" y, con ello, las plurales voces y contextos que desde las más diversas culturas deben ser reconocidas como "filosofía sin más" los múltiples trabajos en esa línea, puede ser mencionado el haber reconocido la existencia de una filosofía andina ${ }^{11}$, por lo que cabe también reconocer su lugar y su tiempo, aun

6 Sepich-Lange, Juan, Latinoamérica, ¿madurez o decadencia?, Mendoza, 1987, p. 280.

7 Pagano Fernández, C., Un modelo de filosofía intercultural: Rodolfo Kusch (1922-1979). Aproximación a la obra del pensador argentino, Aachen, 1999, pp. 10ss.; Abia Yala: liberación de América, en revista Abia Yala, S. J. de Costa Rica, año 3, n 4, enero 1998, pp. 14-16 y sus referencias bibliográficas. También, Fornet-Betancourt, 2004a, p. 41 y nota 59.

8 De Mahieu, J.M., Diccionario de ciencia política, Bs. As., 1966, p. 178-179.

9 Aludamos a los siete Congresos Internacionales de Filosofía Intercultural realizados en Abia Yala, en Asia y en Europa entre 1995 y 2007, todos documentados; para solo referir lo que acontece en el ámbito abiayalense, ver la amplia obra de Raúl Fornet-Betancourt desde 1992. Su Interculturalidad a prueba (2006), al igual que su Crítica intercultural de la filosofía latinoamericana actual, Madrid, 2004 o su Transformación intercultural de la filosofía. Ejercicios teóricos y prácticos de filosofía intercultural desde Latinoamérica en el contexto de la globalización, Bilbao, 2001, consignan gran parte de la bibliografía filosófica intercultural, en la cual nos basamos para este punto. También Salas A., Ricardo (ver) que se ocupa en Chile de la El desde la FI.

10 La FI no desconoce, sin embargo, la gran riqueza que ha aquilatado la filosofía occidental a lo largo de los siglos.

11 Estermann, J., Filosofía andina. Estudio intercultural de la sabiduría autóctona andina, Quito, 1998. 
cuando, como tantas otras filosofías autóctonas, no se ajuste a los parámetros operativos filosóficos universalizados con la expansión imperial conquistadora del Occidente moderno. Este se metamorfosea en globalización, también expansiva y absorbente de toda diversidad $^{12}$ : de la bioecológica y de la humanocultural, como las topadoras de los brutales desmontes de Salta, legitimados por los poderes públicos contra la vida de los pueblos originarios y del futuro inmediato de todos, $\mathrm{y}$ justo ligado a ese proyecto mercantil idolátrico del capital, que establece el compás de la vida y subsume toda sus manifestaciones en él (no solo económicas, sino también políticas, sociales, culturales, religiosas, etc.) poniendo en crisis terminal la misma vida. Con lo dicho ya se puede entrever qué significa para la El ser fundamentada en una FI. Lo primero que en ese sentido podemos anotar es que los reconocimientos de que hablamos implican reconocimientos de tiempos y lugares diversos, es decir, de contextos plurales legítimos. Así, uno de los propósitos de esta FI consiste en dejarse contaminar y reeducar sin profilaxis por las lógicas, pero también por las propuestas antropológicas y consmológicas que cada diversa cultura tiene para aportar al resguardo de las posibilidades de la vida, liquidadas, por el compás ad infinitum de la reducción mercantil ${ }^{13}$ y su política educativa que se impone mediante las presiones de programas económicos para apoyar una educación llamada "de calidad". Esta estrategia del mercado global consiste en desarmar mediante deflaciones categoriales pedagógicas los discursos explicativos de la dependencia y los reclamos de los derechos, entre otros, de los derechos culturales de los pueblos aborígenes. Mediante proyectos que también licuan la misma interculturalidad, tienden a asimilar sus contextos espacio temporales y antropológico-existenciales haciéndolos competentes en mercado y lo que ello civilizatoriamente significa, pues "ignora o minimiza la sabiduría y conocimientos vernáculos considerándolos incapaces de aportar una solución ambiental planetaria. Estos saberes constituyen, sin embargo los pilares sociales que mantienen las bases de la biodiversidad en el mundo"14. Es decir, son saberes, nos dicen los antropólogos de Barbados III, que deberían ser reconocidos y cultivados por modos y contextos establecidos por los propios pueblos y no según el "compás" de la cultura manipuladora de las palancas del poder dominante. Pero, además, y valga como estocada complementaria, debe incluirse no solo como simple información "tolerante" de la llamada "diversidad" o "diferencia", sino en la efectiva praxis de todos los ámbitos y niveles educativos de los pueblos y estados abiayalenses. Clausurar este aspecto es reducir la El a un mero cumplido que no abandona el proyecto de asimilación de aquellos contextos sapienciales y de vida por la lógica invasiva del mercado con sus "fuerzas compulsivas de los hechos" 15 que, como se sabe, determina e impone las pautas direccionales de la educación y sus "reformas" en nuestros estados abiayalenses $^{16}$.

La "comunidad humana", cada vez más interrelacionada, cada vez más acercada por diversos medios y cada vez más accesible, es ella misma un conjunto de culturas en diversidad contextual. Ese acercamiento puede derivar, como se señaló, en un monoculturalismo que subsume las diferencias en la uniformidad o monotonía de lo hegemónico, incapaz de evitar su absolutización pedagógica y de

12 "El primer principio del pensamiento único es tan potente que un marxista distraído no lo cuestionaría: la economía supera a la política... La repetición constante en todos los medios de comunicación de este catecismo por casi todos los políticos, tanto de derecha como de izquierda, le confiere una tal carga de intimidación que ahoga toda tentativa de reflexión libre, y convierte en extremadamente difícil la resistencia contra este nuevo oscurantismo" (Ramonet, I., El pensamiento único, en Le Monde Diplomatique, Ed. Española, julio de 2006, http://altermundismo.blogspot.com/2006/07/n26-el-pensamientounico-ramonet.html

13 Ver Bokelmann, E., Im takt des Geldes..., op. cit., p. 149-183. Hinkelammert, Franz, Cultura de la esperanza y sociedad sin exclusión, S. J. de Costa Rica, 1995, pp. 157-209. Barbados III (1995), pp. 19s.

14 Barbados III, p 20.

15 Hinkelammert, F., Cultura de la esperanza..., op. cit., pp. 309-314.

16 Para este punto, Torres, María Rosa, ¿Mejorar la calidad de la educación básica? Las estrategias del Banco Mundial, en Coraggio, J. L. y Torres, M. R., La educación según el Banco Mundial. Un análisis de sus propuestas y métodos, Bs.As. -Madrid, 1997, pp. 70-154. 
conocimiento, donde "una sola cultura es la que determina las reglas del juego"17; o en un multiculturalismo que lleva a la guerra de culturas o, a lo sumo, se preocupa por "valorar y comprender la diversidad cultural como atributo positivo de nuestra sociedad"; así el lenguaje condescendiente y sin compromiso intercultural de ciertas legislaciones educativas $^{18}$ provenientes de legisladores que, tal se lee en la novela de Gustavo Alfredo Jácome "sin dejar nunca su pose de amos misericordiosos hasta nos hacen el gran favor de saludar dándonos la mano, pero todo-ellos asépticos, no sea que les pasemos la indioemierdería"19. Multi y monoculturalismo se manifiestan inviables para la humanidad. Pues el uno se erige como juez universal de lo humano y el otro aísla en una inconexa tolerancia que a lo máximo puede llegar a esa suerte de folclorización tantas veces turístico-teatral de las culturas, los pueblos y las personas que no alcanzan la simetría material y de poder para imponerse. No faltan los casos en que esa situación cultural se atrinchera en fundamentalismos que petrifican las tradiciones, con lo que, sin embargo, se mata su propia vitalidad y también la posibilidad de una convivencia realmente intercultural.

Ante esto, la interculturalidad o la "hechura" intercultural (Fornet-Betancourt) no puede ser apropiada por definiciones conceptuales ni por tal o cual cultura, porque ya dejaría de ser intercultural. Ninguna cultura es propietaria de la interculturalidad y ningún estamento monocultural, aun cuando esté habilitado "legalmente" para hacerlo, puede determinar el sentido de la educación intercultural sin estar ya previamente en ejercicio efectivo de praxis intercultural. Ejemplo puntual, muy argentino, de cómo se instrumenta la educación intercultural en la carencia más crasa de esa conditio sine qua non para una real educación intercultural, es nada menos que la Ley Nacional de Educación, $\mathrm{N}^{\circ}$ 26.206, que arrincona la interculturalidad como "modalidad" entre otras para los márgenes aborígenes, como si solo nuestros hermanos fueran los destinatarios a quienes se les concede el magnánimo favor de interculturalizarlos, a ellos, desde luego; los demás, la masa homogeneizada por la hegemonía del mercado y de la educación hegemónica, no cae bajo esa discriminatoria "modalidad" de $\mathrm{El}^{20}$. De ese modo, se liquida y entierra el espíritu que se había alcanzado a expresar en la Resol. 107/99 del Consejo Federal de Educación de la RA, el cual, con carácter vinculante, establece (¿aún hoy?) que "el enfoque intercultural debe trascender los ámbitos específicos en los que los profesores y los educandos aborígenes enseñan y aprenden, para permear todos los niveles y modalidades del sistema educativo nacional" (cursivas mías).

Retomando la tesis de este apartado, como se ve, la filosofía en su función cuestionadora de la cultura que se vive como un statu quo que solo cambia de etiquetas y que persiste en la expansión de un proyecto civilizatorio totalitario cifrado en el mito del mercado como norma de ser y hacer ${ }^{21}$, la FI se pregunta si no sería necesario desbaratar el acápite sobre El de la ley nacional argentina para recuperar el espíritu de la misma El en todo el ámbito del país. En efecto, no se puede hablar de El cuando falta el segundo término dialogal de la relación. El es relacionalidad entre culturas, que dialogan desde sus identidades afianzadas para crecer -reitero: educarnos y educar- en humanidad solidaria, nada menos; pues sin interculturalidad la humanidad no tiene perspectivas ni convivenciales ni de supervivencia biológica ${ }^{21}$.

\footnotetext{
17 Panikkar (1996), p. 28ss.

18 Art. 54 Ley Nacional de Educación 26.206 (Argentina) y art. 62 de anteproyecto de Ley de Educación Provincial de la Prov. de Salta, Argentina.

19 Por qué se fueron las garzas, Otalvo, 1979, pp.148

20 Ley Nacional de Educación $N^{\circ}$ 26.206, cap. XI, art. 52. El art. 64 del cap. XIII del Anteproyecto de Ley Provincial de Educación de Salta acusa idéntico déficit insanable en lo intercultural, al transcribir el texto de la Ley Nacional.

21 Fornet-Betancourt, Raúl, Para una crítica filosófica de la globalización, en Fornet-Betancourt, Raúl, Resistencia y solidaridad. Globalización capitalista y liberación, 2003, pp. 74ss.; el mismo trabajo, en alemán, Zur philosophischen Kritik der Globalisierung, en Fornet-Betancourt, Raúl, Kapitalistische Globalisierung und Befreiung. Religiöse Erfahrungen und option für das Leben, Frankfurt, 2000, pp. 75ss.

22 Declaración de Barbados III.
} 
Revista CUHSO volumen $17 \mathrm{~N}^{\circ} 1$

Conclusión

El par de notas traídas acá a modo de estocadas filosóficas quieren alertar acerca de la perspectiva de dilución categorial, como diría Roig, que acosa a la El, instrumentando el bilingüismo como parapeto para desentenderse de una interculturalidad que no se tiene la menor voluntad de ejercitar, por la simple razón de que interculturalidad supone paridad de poder decidir sobre los tiempos y espacios, los rumbos y los contextos que debe seguir la configuración diversificada, tanto en contenidos como en modos y en objetivos de una educación que merezca el nombre de intercultural (Zavala, V.). Esto supone aprender a abrir los espacios de decisiones educativas con seriedad a los espacios contextuales de las diversas culturas, pueblos y gentes, incluyendo en esos espacios dialogales los aspectos que hacen a la organización económica, social y política de los pueblos originarios, como bien lo advierte la Conferencia de Barbados III (p. 21) al recomendar la articulación de las autonomías. En efecto, la El puede también convertirse en un nuevo y eufemístico lugar de coloniaje y sojuzgamiento, a fin de que los interculturalizados mediante una "capacitación" lingüística y de la llamada "modalidad intercultural" fueran reducidos -como en tiempos de las Reducciones- culturalmente y con esa adecuación a los tiempos y espacios monológicos al del proyecto hegemónico global, sean asimilados sistémicamente al mismo, mediante una verdadera desertificación de las alternativas para la naturaleza y para la convivencia humana digna de ese nombre.

50 


\section{Bibliografía}

ALTA, V.; ITURRALDE, D. y LÓPEZ-BASSOLS, M. A. (comps.) (1998). Memorias del Coloquio. Pueblos indígenas y estado en América Latina, Quito.

BONFIL BATALLA, G. (1995). Diversidad y democracia: Un futuro necesario, en Grünberg, G., pp. 9-18.

BIAGINI, HUGO E. Y ROIG, ARTURO A. (comps.) (2007). América Latina hacia su segunda independencia. Memoria y autoafirmación, Bs. As.

CAMDESSUS, M. (1996). Reglas, instituciones y estrategias para el bien común en una economía global, en Revista Estudios sociales, $\mathrm{N}^{\circ}$ 88, trimestre 2, Santiago de Chile, 9-28.

BARBADOS III (1995). Declaración de Barbados III, en Grünberg, G., pp. 19-27.

FORNET-BETANCOURT, R. (1996) (ed.). Kulturen der Philosophie. Dokumentation des I. Internationalen Kongresses für Interkulturelle Philosophie, Aachen. $4^{\text {a }}$ (ed.), Crítica intercultural de la filosofía latinoamericana actual, Madrid.

2006a La interculturalidad a prueba, Aachen.

2006b (Hrsg.), Dominanz der Kulturen und Interkulturalität... Dokumentation des VI. Internationalen Kongresses für Interkulturelle Philosophie, Frankfurt/M- London.

GRÜNBERG, G. (1995) (coord.) Articulación de la diversidad. Tercera Reunión de Barbados, Quito.

HOFFMANN, G. (2006). Interkulturelle Philosophie als Institution? Geschichte und Aufgabe der Kongresse für Interkulurelle Philosophie, en Fornet-Betancourt, Raúl, 2006b, pp. 1323.

PANIKKAR, R. (1996). Filosofía y cultura: una relación problemática, en Fornet-Betancourt, 1996, 15-41.

ROIG, ARTURO A. (2007). Necesidad de una segunda independencia, en Biagini, Hugo E. y Roig, Arturo A., pp. 29-47.

SALAS A., R. (2008). Texto y Contexto: problemas y perspectivas desde la filosofía intercultural, en http://www.alejandria.cl/ram2/ intercultural11062008.ram, Ciclo de Conferencias temáticas en relación a la investigación en educación en contexto indígena e intercultural, Temuco.

TERENA, J. (1998). "Yo puedo ser lo que tú eres sin dejar de ser lo que soy Pero tú nunca serás indio", en Alta, V.; Iturralde, D. e. a, 1998, pp. 239-241.

ZAVALA, V. (2004). La interculturalidad no es solo para los pobres. Una reflexión desde la educación bilingüe en el Perú, en Rolfes de Franco, Margaretha; Neuser, Heinz (eds.), Desarrollo, educación y lucha contra la pobreza, LAPSO, DAAD, Lima, pp. 113-128.

Articulación de la diversidad Barbados III.

http: / / books.google.com.ar/books?id=1_A7 VbDV72oC\&pg=PT1\&lpg=PT1\&dq=declaracio $\mathrm{n}+\mathrm{de}+$ barbados+III+articulacion+de+la+dive rsidad+rio+de+janeiro\&source=web\&ts $=K$ DfK6Sltz\&sig=ryTqTW9ChpNe7jyqCDVrWxqsdg\&hl=es\&sa=X\&oi=book_result\&resnum=4\&ct= result\#PPA19,M1

La Ley 26.206 de Educación Nacional Argentina, Art. 11. Fines y objetivos de la política educativa nacional: l) Fortalecer la centralidad de la lectura y la escritura, como condiciones básicas para la educación a lo largo de toda la vida, la construcción de una ciudadanía responsable y la libre circulación del conocimiento (...)

ñ) Asegurar a los pueblos indígenas el respeto a su lengua y a su identidad cultural, promoviendo la valoración de la multiculturalidad en la formación de todos/as los/as educandos/ as $(\ldots)$

s) Promover el aprendizaje de saberes científicos fundamentales para comprender

y participar reflexivamente en la sociedad contemporánea (...)

v) Promover en todos los niveles educativos y modalidades la comprensión del

concepto de eliminación de todas las formas de discriminación (...) 